\title{
Effect of Professional Satisfaction on Learning Engagement in Undergraduates Majoring in Preschool Education: Mediating Role of Professional Commitment
}

\author{
Meirong Chen \\ Education Department, Nanchang Normal University, Nanchang, China \\ Email: chenmeirong1227@163.com
}

How to cite this paper: Chen, M. R. (2018). Effect of Professional Satisfaction on Learning Engagement in Undergraduates Majoring in Preschool Education: Mediating Role of Professional Commitment. Psychology, 9, 2250-2260.

https://doi.org/10.4236/psych.2018.98128

Received: July 30, 2018

Accepted: August 28, 2018

Published: August 31, 2018

Copyright $\odot 2018$ by author and Scientific Research Publishing Inc. This work is licensed under the Creative Commons Attribution International License (CC BY 4.0).

http://creativecommons.org/licenses/by/4.0/

\section{(c) (i) Open Access}

\begin{abstract}
Objective: To explore the influence mechanism of the professional satisfaction of preschool education majors undergraduate on Study Engagement. Methods: 750 subjects were investigated by using professional satisfaction questionnaire, professional commitment questionnaire and learning engagement questionnaire. Results: 1) College students majoring in preschool education professional satisfaction and professional commitment are in the middle level, but a higher degree of learning engagement; 2) For undergraduates of preschool education professional satisfaction, learning engagement and the level of professional commitment have significant effects on the academic achievement; 3) There is a significant positive correlation among professional satisfaction, professional commitment and learning engagement. Conclusion: The professional commitment mediated the effect of the professional satisfaction on learning engagement of preschool education college students.
\end{abstract}

\section{Keywords}

Preschool Education Professional Satisfaction, Learning Engagement, Professional Commitment

\section{Introduction}

As China's two-child policy carried out and the emergence of new baby boomers, people's demand for preschool education is more intense and prominent. Therefore, parents pay more attention to the quality of preschool education, because preschool teachers are the key factor affecting the quality of preschool 
education. But in essence, the events involve the focus and dedication of pre-service training of pre-school students majoring in education, namely, the learning engagement.

With the rise of positive psychology, learning engagement was put forward as the opposition to the learning burnout and it obtained the attention of the researchers. Learning engagement refers to a positive, full emotion and cognitive state of mind associated with learning, research, and employment (Fang, Shi, \& Zhang, 2008). To a certain extent, students' learning engagement has become one of the important factors influencing the quality of higher education (Kahu, 2013). The theory of student participation (Astin, 1999), the theory of student engagement (Gunuc \& Kuzu, 2015) and the three-dimensional model of learning engagement (Ladd et al., 2017) all believe that learning engagement is a more reasonable predictive index of the quality of higher education than resource input and the reputation of academies. In addition, learning involvement also affects students' future career and the quality of education teaching. Therefore, exploring the influence factors and the mechanism of action of learning in preschool education college students, not only can evaluate the quality of higher education, but also helps to predict the quality of kindergarten education, as for improving the quality of preschool education, promoting home and school integration in the preschool education and ensuring preschool education system can meet the needs of the people.

The satisfaction is a kind of subjective feeling, and the degree of satisfaction is the indicators of subjective perception (that is, the degree of feeling), including the two aspects of subjective expectation (Internal needs) and objective satisfaction. Professional satisfaction is the degree to which student feels subjectively about his/her major and related factors. Professional satisfaction is the source of college students' professional learning motivation, which has a profound impact on the quality of life of college students, and is closely related to employment tendency, employment expectation and career planning (Liu, 2014). Professional satisfaction, as a kind of emotion, exerts important influence on their learning engagement of the positive behaviors. The higher professional satisfaction, the higher interest and enthusiasm in learning, so they are actively engaged in learning. There is a significant positive correlation between professional satisfaction and learning engagement (Liu et al., 2017).

However, it is not clear that how professional satisfaction affects learning engagement. And the introduction of intermediary variable analysis can reveal that the independent variable "how" plays a role in the dependent variable (Wen \& Ye, 2014). Therefore, we should explore the intermediary mechanism that professional satisfaction affects learning engagement.

Professional commitment refers to the positive attitude and behavior of college students who identify with their major and are willing to make corresponding efforts (Lian, Yang, \& Wu, 2005). According to the theory of professional identity that the stronger the professional commitment of students, the stronger learning motivation of the students (Bin, 2016). The model of participation identity theory 
also thinks that the higher the recognition degree of individuals, the more positive of individuals in their activity participation; that is, the more one approves his/her professional, the more positive the emotional state and behavior of his/her engagement. Empirical studies have found a significant correlation between engagement and commitment (Schaufeli et al., 2002); Many studies have shown that professional commitment and learning engagement has significant positive correlation, and professional commitment especially emotional commitment can effectively predict learning engagement (Cai \& Wang, 2017; Duan \& Li, 2008; Ding, 2015). Commitment is the most important predictor of college students' learning engagement (Zhang, Bian, \& Xu, 2008). Therefore, professional commitment may be an intermediary variable that affects the learning engagement of college students. Some studies have shown that satisfaction can affect commitment behavior, professional satisfaction is positively correlated with professional commitment, and it is an important predictor of professional commitment (Liu, 2014).

To sum up, professional satisfaction can promote professional commitment to increase learning engagement. Therefore, professional satisfaction may increase students' learning engagement through professional commitment, and this study theory hypothesis model is shown in Figure 1.

\section{Methodology}

\subsection{Sample Population}

Research objects are 750 students (average age $20.58 \pm 8.01$ ) majoring in preschool education professional that were selected from several universities. Due to the particularity of the professional, the proportion of boys and girls differ greatly, the amount of boys is only 26 , the rest are girls. There are 242 freshmen, 351 sophomores, 133 juniors, 24 seniors.

\subsection{The Instrument Used}

\subsubsection{Professional Commitment Scale}

College student professional commitment scale compiled by Lian et al. (2006) was adopted. This scale, a total of 27 items, including the four dimensions of emotional commitment (9 items), ideal commitment ( 7 items), normative commitment (5 items) and continuance commitment (6 items), is using self-reported

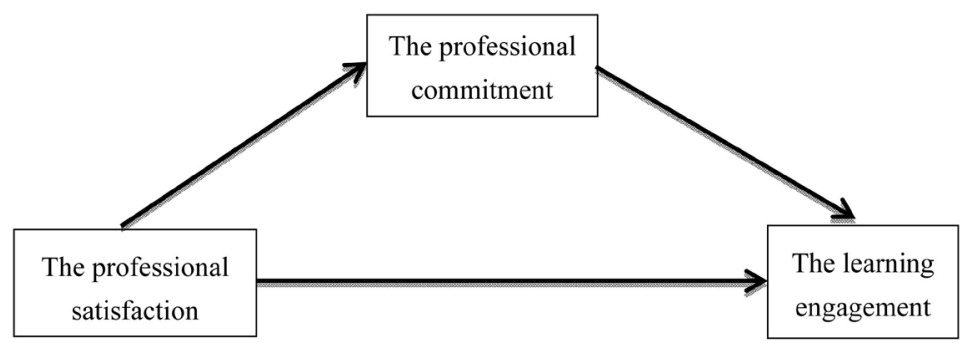

Figure 1. The relation model of the professional satisfaction and the learning engagement. 
Likert 5 point scoring system, from 1 (completely does not comply with) to 5 (completely in line with). Then calculate the item mean of each factor separately, the higher the score, the stronger the commitment of the corresponding dimension. The coefficient of the total scale is 0.927 , the split-half reliability is 0.831 . The scale has a good distinction degree, and there is a significant correlation among each item and its subordinate factors and the total scale. In this study, the questionnaire's alpha coefficient is 0.928 .

\subsubsection{Professional Satisfaction Questionnaire. Professional Satisfaction} Questionnaire Complied by Liu (2014) Was Adopting

Questionnaire is formed by the five factors that practical teaching, teaching resources, curriculum construction, professional prospect and construction of learning style. The questionnaire has a total of 27 items that each item is adopting the method of five-point Likert type scoring, from 1 (not satisfied at all) to 5 (quite satisfied), the scores can be calculated by the sum of each item, the higher the score, the higher professional satisfaction, better fit of the questionnaire and the internal consistency, In this study the questionnaire of alpha coefficient is 0.961 .

\subsubsection{Learning Engagement Scale (Schaufeli et al., 2002)}

"Learning engagement scale (UWES-S)" was revised by Fang et al. (2008), three core dimensions of the scale are vigor, dedication and absorption. The scale has 17 items totally, adopting seven-point (from 1 (never) to 7 (always/everyday)) Likert scale, the higher score, suggests more learning engagement. The internal consistency reliability of the scale is between 0.82 and 0.95 . The correlation coefficient of the scale is significant which ranging from 0.76 to 0.77 . The item load is between 0.42 and 0.81 , therefore, it has a good fitting index. In this study, the questionnaire's alpha correlation coefficient is 0.961 .

\section{Findings}

\subsection{The Control and Inspection of Common Method Bias}

There may be a common method deviation due to the self-report method used in this study to collect data. Therefore, the examination of common method bias is essential. The research adopted the Control unmeasured single method latent factor method to verify the common method bias. Results show that eight factors characteristic root is more then 1, the first factor only can explain $35.24 \%$, less than $40 \%$ of the critical standards. So, there are not serious common method biases (Wen, Chang, Hau, \& Liu, 2004).

\subsection{The Relationship among the Professional Commitment, Professional Satisfaction and Learning Engagement}

This study requires participants to fill out "a recent years class comprehensive ranking" and "class size". According to the regulations of school management, the top thirty percent of the participants will receive a corresponding (first-class to third-class) scholarship. Divides its comprehensive ranking and class number 
to get corresponding comprehensive evaluation ranking, students' academic achievements are as the judging indexes to evaluate whether students' academic records good or not, which were divided into five levels. the top $30 \%$ is for the first level, $31 \%$ - 50\% for the second level, 51\% - 70\% third, $71 \%$ - 91\% fourth and $91 \%-100 \%$ for the fifth level.

In order to know about the relationship among the professional commitment, professional satisfaction and learning engagement, the total score of the professional commitment, the professional satisfaction and the learning engagement in the first $27 \%$ high-score group and the last $27 \%$ low-score group, the high group and the low group 180 participates, a total of 360 subjects. In this article, we applied independent-samples $t$ test to the professional commitment, professional satisfaction and learning engagement with their comprehensive evaluation results rank in a recent year. The results show that the three variables of professional commitment, professional satisfaction and learning engagement, the comprehensive ranking scores of high group subjects is significantly higher than the low-score group's. Details can be seen from Table 1.

\subsection{The Correlation Test between Professional Satisfaction, Professional Commitment and Learning Investment}

The descriptive analysis of professional satisfaction, professional commitment and learning engagement found that. Each dimension of professional satisfaction and professional commitment, and the total score are at a moderate level, see from Table 2. The relative analysis found that each dimension of satisfaction. Is positive related to the each dimension of the professional commitment; the each dimension of professional satisfaction is positive related to the each dimension of learning engagement. Each dimension of commitment is positive related to learning engagement. See from Table 3.

\subsection{Mediating Effect Model Test}

Adopting the three-step test of Wen Zhonglin et al. (2004) that is first test the regression equation between independent variable and dependent variable is test whether the regression coefficient is significant or not, then test the regression equation of the independent variable and mediating variable, testing whether the regression equation is significant or not; lastly, test the regression equation of the independent variable and mediating variable to the dependent variable. Test the

Table 1. The correlation model of the professional satisfaction and the learning engagement.

\begin{tabular}{ccccc}
\hline & $\begin{array}{c}\text { High-score group } \\
(\mathrm{M} \pm \mathrm{SD})\end{array}$ & $\begin{array}{c}\text { Low-score group } \\
(\mathrm{M} \pm \mathrm{SD})\end{array}$ & $\mathrm{t}$ & sig \\
\hline Professional commitment & $3.78 \pm 1.78$ & $3.30 \pm 1.61$ & 2.70 & 0.007 \\
Professional satisfaction & $3.66 \pm 1.75$ & $3.28 \pm 1.51$ & 2.20 & 0.029 \\
Learning engagement & $4.17 \pm 1.76$ & $3.11 \pm 1.51$ & 6.15 & 0.000 \\
\hline
\end{tabular}


Table 2. Descriptive statistics of each variable $(\mathrm{N}=750)$.

\begin{tabular}{ccc}
\hline & Mean Value & Standard deviation \\
\hline Emotion Commitment & 3.318 & 0.614 \\
Ideal commitment & 3.340 & 0.685 \\
Normative Commitment & 3.723 & 0.734 \\
Continuance commitment & 3.134 & 0.585 \\
The Total score of Professional Commitment & 3.379 & 0.568 \\
The Practice of Internship & 3.468 & 0.664 \\
Teacher Resources & 3.611 & 0.697 \\
Curricula Construction & 3.477 & 0.709 \\
Professional Prospects & 3.527 & 0.757 \\
Construction of School Style & 3.557 & 0.852 \\
The Total Score of Professional Satisfaction & 3.528 & 0.640 \\
Vigour & 4.126 & 1.052 \\
Dedication & 4.461 & 1.055 \\
Concentration & 4.319 & 4.302 \\
\hline
\end{tabular}

Table 3. Correlation analysis results of various variables.

\begin{tabular}{|c|c|c|c|c|c|c|c|c|c|c|c|c|c|c|c|}
\hline variables & 1 & 2 & 3 & 4 & 5 & 6 & 7 & 8 & 9 & 10 & 11 & 12 & 13 & 14 & 15 \\
\hline 1 & 1 & & & & & & & & & & & & & & \\
\hline 2 & $0.82^{\star * * *}$ & 1 & & & & & & & & & & & & & \\
\hline 3 & $0.67^{\star * \star}$ & $0.67^{\star * *}$ & 1 & & & & & & & & & & & & \\
\hline 4 & $0.71^{* * *}$ & $0.69^{* * *}$ & $0.47^{* * *}$ & 1 & & & & & & & & & & & \\
\hline 5 & $0.92^{* * *}$ & $0.92^{\star * *}$ & $0.83^{* * *}$ & 0.81 & 1 & & & & & & & & & & \\
\hline 6 & $0.53^{* * *}$ & $0.56^{* * *}$ & $0.49^{* * *}$ & 0.46 & $0.59^{* * *}$ & 1 & & & & & & & & & \\
\hline 7 & $0.50^{* \star *}$ & $0.50^{* * *}$ & $0.51^{* * *}$ & 0.37 & $0.55^{* * *}$ & $0.76^{* * *}$ & 1 & & & & & & & & \\
\hline 8 & $0.49^{* * *}$ & $0.51^{* * *}$ & $0.48^{* * *}$ & 0.42 & $0.55^{* * *}$ & $0.75^{* * *}$ & $0.76^{* * *}$ & 1 & & & & & & & \\
\hline 9 & $0.37^{* * *}$ & $0.39^{* * *}$ & $0.37^{\star * *}$ & 0.29 & $0.41^{* * *}$ & $0.56^{* * *}$ & $0.63^{* * *}$ & $0.62^{* * *}$ & 1 & & & & & & \\
\hline 10 & $0.45^{* * *}$ & $0.49^{* * *}$ & $0.42^{* * *}$ & 0.38 & $0.50^{* * *}$ & 0.64 & $0.68^{* * *}$ & $0.76^{* * *}$ & $0.59^{* * *}$ & 1 & & & & & \\
\hline 11 & $0.54^{* * *}$ & $0.57^{* * *}$ & $0.52^{* * *}$ & $0.44^{* * *}$ & $0.60^{* * *}$ & $0.85^{* * *}$ & $0.88^{\star * *}$ & $0.90^{* * *}$ & $0.81^{\star * *}$ & $0.86^{* * *}$ & 1 & & & & \\
\hline 12 & $0.53^{* * *}$ & $0.48^{* * *}$ & $0.33^{* * *}$ & $0.43^{* * *}$ & $0.51^{* * *}$ & $0.46^{* * *}$ & $0.41^{* * *}$ & $0.47^{* * *}$ & $0.40^{\star * *}$ & $0.43^{* * *}$ & $0.50^{* * *}$ & 1 & & & \\
\hline 13 & $0.58^{* * *}$ & $0.55^{\star * *}$ & $0.46^{* * *}$ & $0.43^{* * *}$ & $0.58^{* * *}$ & $0.48^{* * *}$ & $0.44^{* * *}$ & $0.50^{* * *}$ & $0.41^{\star * *}$ & $0.45^{* * *}$ & $0.53^{\star * *}$ & $0.80^{* * *}$ & 1 & & \\
\hline 14 & $0.54^{* * *}$ & $0.49^{* * *}$ & $0.37^{* * *}$ & $0.44^{* * *}$ & $0.52^{* * *}$ & $0.45^{* * *}$ & $0.42^{* * *}$ & $0.46^{* * *}$ & $0.38^{* * *}$ & $0.38^{* * *}$ & $0.48^{* * *}$ & $0.80^{\star * *}$ & $0.84^{* * *}$ & 1 & \\
\hline 15 & $0.59^{\star \star \star}$ & $0.54^{\star \star *}$ & $0.41^{* * *}$ & $0.46^{* \star *}$ & $0.57^{* * *}$ & 0.50 & $0.45^{\star * *}$ & $0.51^{\star * *}$ & $0.42^{\star * *}$ & $0.45^{\star * *}$ & $0.54^{\star * *}$ & $0.93^{\star * *}$ & $0.94^{\star * *}$ & $0.94^{\star * *}$ & 1 \\
\hline
\end{tabular}

Notes: The numerical meaning of the variables: $1=$ Emotion Commitment Factor, $2=$ Ideal Commitment Factor, $3=$ Normative Commitment, $4=$ Continuance Commitment Factor, $5=$ The Total score of Professional Commitment; $6=$ Curricula Construction, $7=$ Teacher Resources, $8=$ The Practice of Internship, $9=$ Construction of School Style, $10=$ Professional Prospects, $11=$ The Total Score of Professional Satisfaction; $12=$ Vigour, $13=$ Dedication, 14 $=$ Concentration, $15=$ The Total Score of Learning Engagement. ${ }^{* * * \text { indicating } P<0.001}$. 
regression coefficient significant or not. According to the mediation model diagram 1, this study adopts the sequential test method to test the mediating effect, and the result is shown in Tables 4-6: The standardization regression coefficient is $0.534(\mathrm{t}=17.287, p<0.001)$, the standardization of $\mathrm{a}$ and $\mathrm{b}$ values are $0.60(\mathrm{t}=$ 20.538, $p<0.001)$ and $0.297(\mathrm{t}=8.282, p<0.001$ respectively, the standardization of c' value is $0.395(\mathrm{t}=11.069, p<0.001)$, extremely high the significant. Therefore, the hypothesis is right that the professional commitment as the mediating effect of the professional satisfaction and learning engagement, and the mediating effect accounts for the total effect $33.337 \%(\mathrm{ab} / \mathrm{c})$, seen from Figure 2.

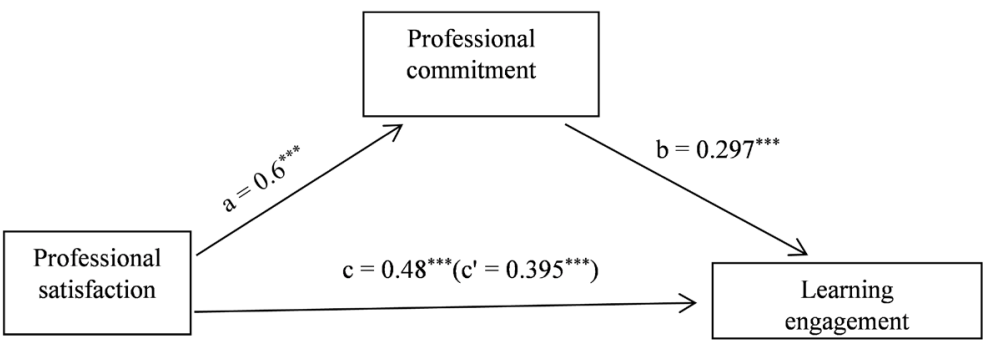

Figure 2. The mediating effect model of professional commitment on professional satisfaction and learning investment.

Table 4. Regression coefficient C test.

\begin{tabular}{|c|c|c|c|c|c|}
\hline \multirow{2}{*}{ Model } & \multicolumn{2}{|c|}{ Non-standard coefficient } & \multirow{2}{*}{$\begin{array}{c}\text { standard coefficient } \\
\text { Beta }\end{array}$} & \multirow{2}{*}{$t$} & \multirow{2}{*}{$P$} \\
\hline & B & Standard error & & & \\
\hline (constant) & 1.363 & 0.173 & & 7.889 & 0.000 \\
\hline $\begin{array}{l}\text { The total score of } \\
\text { professional satisfaction }\end{array}$ & 0.833 & 0.048 & 0.534 & 17.287 & 0.000 \\
\hline
\end{tabular}

Dependent variable: Learning engagement.

Table 5. Regression coefficient a test.

\begin{tabular}{|c|c|c|c|c|c|}
\hline \multirow{2}{*}{ Model } & \multicolumn{2}{|c|}{ Non-standard coefficient } & \multirow{2}{*}{$\frac{\text { standard coefficient }}{\text { Beta }}$} & \multirow{2}{*}{$t$} & \multirow{2}{*}{$P$} \\
\hline & $\mathrm{B}$ & Standard error & & & \\
\hline (constant) & 1.499 & 0.093 & & 16.116 & 0.000 \\
\hline $\begin{array}{l}\text { The total score of } \\
\text { professional satisfaction }\end{array}$ & 0.533 & 0.026 & 0.600 & 20.538 & 0.000 \\
\hline
\end{tabular}

Dependent variable: the total score of professional satisfaction.

Table 6. Regression coefficient b, c' test.

\begin{tabular}{|c|c|c|c|c|c|}
\hline \multirow{2}{*}{ Model } & \multicolumn{2}{|c|}{$\begin{array}{c}\text { Non-standard } \\
\text { coefficient }\end{array}$} & \multirow{2}{*}{$\begin{array}{c}\text { standard } \\
\text { coefficient } \\
\text { Beta }\end{array}$} & \multirow{2}{*}{$\mathrm{t}$} & \multirow{2}{*}{ Sig. } \\
\hline & $\mathrm{B}$ & $\begin{array}{l}\text { Standard } \\
\text { error }\end{array}$ & & & \\
\hline (constant) & 0.323 & 0.186 & & 1.734 & 0.083 \\
\hline The total score of professional satisfaction & 0.463 & 0.056 & 0.297 & 8.282 & 0.000 \\
\hline The total score of professional commitment & 0.694 & 0.063 & 0.395 & 11.009 & 0.000 \\
\hline
\end{tabular}

Dependent variable: learning engagement. 


\section{Discussion}

\subsection{The General Situation of College Students' Professional Satisfaction, Professional Commitment and Learning Engagement}

The general situation of professional satisfaction, professional commitment and learning engagement of preschool major college students. There are researches showed about preschool education major undergraduates show that their professional satisfaction and professional commitment at a medium level (Chen, Zhang, \& Shi, 2013; Zhang \& Ji, 2012), which is consistent with the results of this study. This may be related to many students and parents tending to consider more about employment when they fill out college application. Most of the current students in preschool education professional are girls from the countryside, they and their parents realize that the professional prospects of the major is relatively good, but when they enter into the professional learning especially after probation, they found preschool teachers work overload, low pay and the shortage of social security system that resulting in a decline in their level of professional satisfaction and professional commitment, some students' longing dream of kindergarten teacher were broken by reality that be children's nanny. Some researchers also believe that this may be related to the way of admission (Chen \& Zheng, 2016), teacher resources and teaching level (Chen, Zhang, \& Shi, 2013).

The study also found that the preschool education major undergraduates and the rising number of college graduates have high learning engagement. That may be the fierce competition in the job market, and the rising number of college graduates, which increase the pressure of graduates invisibly. In order to get achievements in the job market in the future, they must obtain the corresponding honor, scholarship, especial to the undergraduate of preschool major, the job market pay special attention to the skills of stinging, paining, playing the piano, dancing, etc. However, many of them before starting from zero when they studying this major. Therefore, they have to study hard, increase their learning engagement.

\subsection{The Relationship between Professional Satisfaction and Professional Commitment}

Many studies have found that professional identity and learning engagement have a significant correlation, and it can effectively predict the learning engagement (Chen, 2013; Liu et al., 2014). Both professional identity and professional satisfaction are emotion response to the professional learning and they are similar in essence. Professional commitment is the results of professional identity. There are researches indicating that professional commitment is an important individual characteristic variables of the learning engagement. The results of this study indicate that professional satisfaction and learning engagement can significantly positive related to and predict each other in the undergraduates of preschool major (Fredricks et al., 2004). The results are consistent with many other 
research results (Chen \& Xu, 2013; Wei, 2013; $\mathrm{Li}, 2016)$. The reasons are in the following. Firstly, if students are satisfied with their major, it can produce the corresponding satisfaction and form a pleasant and positive emotional experience that can improve the commitment level to their major. As mentioned in the definition of professional commitment, only on the premise that students approve their professional can they take learning action actively.

Secondly, the higher the level of commitment the higher the level of engagement. Both professional satisfaction and professional commitment have the emotional component, but learning engagement has the component of emotion and behavior. Positive emotions will become the motivation of the behavior, and the more positive emotions, the stronger the behavior of persistent. That's to say, the higher the degree of satisfaction and commitment, the stronger the learning engagement.

The results of this study show that professional commitment plays an intermediary role between professional satisfaction and learning engagement. This means those students who are satisfied with the preschool major are often show strong emotion to their profession that would rather not change it, because they have high expectation to their major development, thinking themselves could overcome difficulties to welcome the challenge in their learning and mastering the professional knowledge and to realize their professional ideal. They are willing to follow the specifications and requirements of their professional. They are not easy to get tired but absorbing in the process of learning and experiencing the corresponding happiness; that is to say, the four respect of emotion commitment, ideal commitment, continuance commitment, normative commitment, from the professional commitment, which could indirectly affect their vigour, dedication and concentration of the learning engagement.

\subsection{The Influence of Professional Satisfaction, Professional Commitment and Learning Engagement on Academic Performance}

The results of this study show that the academic performance of subjects who have high degree of professional satisfaction is significantly better than those subjects with low degree of satisfaction. This trend is also reflected in the professional commitment and learning engagement.

Those show that in the future, we can improve students' learning engagement by improve students' professional satisfaction; but, because the professional commitment acts an intermediate role, we can improve their academic achievements by improving the level of professional commitment. To be specific, in the professional voluntary application form, we can introduce the job orientation, the nature of work and job requirement of the preschool education major. At the same time, students could be allowed to adjust their majors after students enter school a period of time; school related departments could conduct vocational interest tests for the professional students who are applying for the application of the adjustment major to select out some students who have high degree satisfaction 
of the preschool professional. In order to truly implement the requirement that basic popularization of preschool education to reserve a good number of preschool teachers continually improves the level of preschool education.

\section{Funding}

This work was supported by Jiangxi province university humanities and social science planning fund project "Study on the impact of pre-service kindergarten teachers' professional commitment on academic achievement and career planning", standard number: XL1412.

\section{Conflicts of Interest}

The authors declare no conflicts of interest regarding the publication of this paper.

\section{References}

Astin, A. W. (1999). Student Involvement: A Developmental Theory for Higher Education. Journal of College Student Personnel, 40, 297-308.

Bin, S. (2016). A study on the Relationship among College Students' Occupational Values, Professional Commitment and Learning Engagement. Master's Degree Thesis, Harbin: Harbin Normal University.

Cai, W. B., \& Wang, L. (2017). On the Relations between Students' Learning Engagement, Professional Commitment and Learning Strategies. Journal of Guangxi Normal University (Philosophy and Social Sciences Edition), 53, 103-109.

Chen, S. P., \& Zheng, J. (2016). Reflection and Transcendence: The Employment Competitiveness of Preschool Education Graduates. Heilongjiang Researches on Higher Education, 265, 125-128.

Chen, S. P., Zhang, Y. M., \& Shi, Q. (2013). Research on the Development Characteristics of Professional Commitment of Preschool Education Undergraduates its Education Countermeasures. Education Research Monthly, No. 9, 86-90.

Chen, Y. G. (2013). The Relationship among Future Orientation, Specialty Identity and Study Engagement. Sichuan University of Arts and Science Journal, 23, 91-95.

Chen, Y. W., \& Xu, P. P. (2013). Improving Academic Engagement for Undergraduates in Business School-A Perspective of Major Commitment in Learning Psychology. China Higher Education Research, No. 9, 94-98.

Ding, Y. (2015). Research on Mechanism of Psychological Capital Influencing Learning Engagement-Based on Mediating Effect of Professional Commitment of College Students. Education and Teaching Research, 29, 48-52.

Duan, L. S., \& Li, Y. X. (2008). The Relationship between Professional Commitment, Learning Burnout and Learning Engagement of Undergraduates. China Journal of Health Psychology, 16, 407-409.

Fang, L. T., Shi, K., \& Zhang, F. H. (2008). Research on Reliability and Validity of Utrecht Work Engagement Scale-Student. Chinese Journal of Clinical Psychology, 16, 618-620.

Fredricks, J. A., Blumenfeld, P. C., \& Paris, A. H. (2004). School Engagement: Potential of the Concept, State of the Evidence. Review of Educational Research, 74, 59-109. https://doi.org/10.3102/00346543074001059 
Gunuc, S., \& Kuzu, A. (2015). Student Engagement Scale: Development, Reliability and Validity. Assessment \& Evaluation in Higher Education, 40, 587-610. https://doi.org/10.1080/02602938.2014.938019

Kahu, E. R. (2013). Framing Student Engagement in Higher Education. Studies in Higher Education, 38, 758-773. https://doi.org/10.1080/03075079.2011.598505

Ladd, G. W., Ettekal, I., \& Kochenderfer-Ladd, B. (2017). Peer Victimization Trajectories from Kindergarten through High School: Differential Pathways for Children's School Engagement and Achievement? Journal of Educational Psychology, 109, 826-841. https://doi.org/10.1037/edu0000177

Li, Y. (2016). Investigation and Study on the Current Situation of Educational Investment for Postgraduates of Pedagogy-Take N School as an Example. Master's Degree Thesis, Nanjing: Nanjing Normal University.

Lian, R., Yang, L., \& Wu, L. (2005). Relationship between Professional Commitment and Learning Burnout of Undergraduates and Scales Developing. Acta Psychological Sinica, 37, 632-636.

Lian, R., Yang, L., \& Wu, L. (2006). A Study on the Professional Commitment and Learning Burnout of Undergraduates and Their Relationship. Psychological Science, 29, 47-51.

Liu, H. (2014). Relationship between Undergraduates' Professional Satisfaction and Professional Commitment. Master's Thesis, Jingzhou: Yangtze University.

Liu, X., Zhong, D., \& Hang, J. (2017). The Relationship between Undergraduates' Professional Satisfaction and Learning Engagement and Learning Effects. Higher Education Exploration, No. 2, 58-63.

Liu, Y., Xue, Q., Jiang, Z., Zou, Y., \& Wang, N. (2014). Study on the Relationship between Word Engagement and Specialty Identity of Medical Students. Chinese Journal of Medical Education, 34, 403-407.

Schaufeli, W. B., Martinez, I. M., Pinto, A. M., Salanova, M., \& Bakker, A. B. (2002). Burnout and Engagement in University Students a Cross-National Study. Journal of Cross-Cultural Psychology, 33, 464-481. https://doi.org/10.1177/0022022102033005003

Wei, Y. (2013). A Correlational Study of Professional Commitment and Learning Engagement of Normal Undergraduate Students. Journal of Kaili University, 31, 130-132.

Wen, Z., \& Ye, B. J. (2014). Different Methods for Testing Moderated Mediation Models: Competitors or Backups? Acta Psychological Sinica, 46, 714-726. https://doi.org/10.3724/SP.J.1041.2014.00714

Wen, Z., Chang, L., Hau, K., \& Liu, H. (2004). Testing and Application of the Mediating Effects. Acta Psychological Sinica, 36, 614-620.

Zhang, J., \& Ji, Y. (2012). The Characteristics of the Development of College Students' Professional Commitment and the Educational Countermeasures. Contemporary Educational Science, No. 9, 30-32.

Zhang, X., Bian, X., \& Xu, G. (2008). Relationship between the Learning Engagement and Stress of Senior High School Students. China Journal of Health Psychology, 16, 1246-1248. 